\title{
Annonce de mise en ligne sur Persée
}

\section{(2) OpenEdition}

\section{Journals}

Édition électronique

URL : https://journals.openedition.org/ceg/14534

DOI : $10.4000 /$ ceg. 14534

ISSN : 2605-8359

Éditeur

Presses Universitaires de Provence

\section{Édition imprimée}

Date de publication : 27 mai 2021

ISBN : 979-10-320-0315-2

ISSN : 0751-4239

\section{Référence électronique}

"Annonce de mise en ligne sur Persée », Cahiers d'Études Germaniques [En ligne], 80 | 2021, mis en ligne le 09 septembre 2021, consulté le 03 décembre 2022. URL : http://journals.openedition.org/ceg/ 14534 ; DOI : https://doi.org/10.4000/ceg.14534 

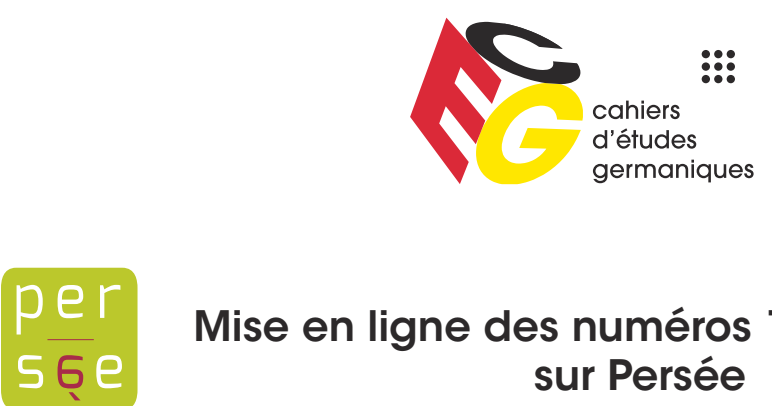

\section{Mise en ligne des numéros 1 à 61 des CEG sur Persée}

Les numéros récents des Cahiers d'Études Germaniques sont consultables en ligne sur le portail OpenEdition (https://journals.openedition.org/ceg). Pour compléter cette offre numérique, les CEG s'apprêtent à mettre en ligne l'ensemble de leurs archives de 1972 à 2011 (numéros 1 à 61). Celles-ci rejoindront le portail de diffusion public et gratuit Persée (https://www.persee.fr), mis en place avec le soutien du ministère de l'Enseignement supérieur, de la Recherche et de l'Innovation.

Afın de mener à bien ce projet dans le respect des auteurs ou de leurs ayants droit, il est nécessaire qu'ils donnent (à titre non exclusif) l'autorisation explicite de reproduire et de diffuser sur ce portail les articles ou contributions qu'ils ont publiés dans les $C E G$.

Si vous avez contribué aux numéros 1 à 61, nous espérons que vous accorderez une nouvelle fois votre confiance à l'équipe des $C E G$ en renseignant le coupon réponse ci-après et en le renvoyant à Nathalie Schnitzer (nathalie.schnitzer@univ-amu.fr), responsable de l'édition électronique de la revue.

\section{Per Online-Publikation der Nummern 1 bis 61 der CEG sq्e auf Persée}

Die neueren Ausgaben der Cahiers d'Études Germaniques sind online auf dem OpenEdition-Portal (https://journals.openedition.org/ceg) verfügbar. Um dieses digitale Angebot zu ergänzen, wird die Zeitschrift in Kürze auch ihre Jahrgänge 1972 bis 2011 online stellen. Die entsprechenden Nummern (Nr.1 bis Nr.61) sollen auf dem kostenlosen öffentlichen Verbreitungsportal Persée (https://www.persee.fr) zugänglich gemacht werden, das mit Unterstützung des französischen Ministeriums für Hochschulbildung, Forschung und Innovation eingerichtet wurde.

Damit dieses Projekt unter Wahrung der Interessen der Autoren oder ihrer Rechtsnachfolger realisiert werden kann, ist es notwendig, dass sie (auf nichtexklusiver Basis) die Online-Publikation ihrer in den CEG veröffentlichten Artikel oder Beiträge auf diesem Portal ausdrücklich genehmigen.

Wenn Sie zu den Nummern 1 bis 61 beigetragen haben, hoffen wir, dass Sie den $C E G$ erneut Ihr Vertrauen aussprechen, indem Sie das beigefügte Formular unterschreiben und an Nathalie Schnitzer (nathalie.schnitzer@univ-amu.fr), die für die elektronische Ausgabe der CEG zuständig ist, zurückzusenden. 


\section{Autorisation de diffusion en ligne Coupon réponse pour les auteur.es}

Je soussigné.e

autorise à titre non exclusif les Cahiers d'Études Germaniques à reproduire et à diffuser dans le cadre du programme Persée les articles et contributions publiés sous mon nom dans ladite revue ainsi que les traductions et les illustrations dont je suis l'auteur.e.

Fait à le

Signature

\section{Einverständniserklärung für die Online-Publikation Antwort-Coupon für Autorlnnen}

Ich, der/die Unterzeichnete

erkläre mich damit einverstanden, dass die unter meinem Namen in der Cahiers d'Études Germaniques veröffentlichten Artikel und Beiträge sowie Übersetzungen und Illustrationen, deren AutorIn ich bin, im Rahmen des Persée-Programms auf nicht-exklusiver Basis online publiziert werden dürfen.

Ort

Datum 


\section{Autorisation de diffusion en ligne Coupon réponse pour les ayants droit}

Je soussigné.e,

agissant en qualité d'ayant droit de

autorise à titre non exclusif les Cahiers d'Études Germaniques à reproduire et à diffuser dans le cadre du programme Persée les articles et contributions publiés sous son nom dans ladite revue ainsi que les traductions et les illustrations dont il ou elle est l'auteur .e.

Fait à Le

Signature

\section{Einverständniserklärung für die Online-Publikation Antwort-Coupon für Rechtsnachfolgerlnnen}

Ich, der/die Unterzeichnete

als RechtsnachfolgerIn von Herrn/ Frau

erkläre mich damit einverstanden, dass die unter ihrem/ seinem Namen in der Cahiers d'Études Germaniques veröffentlichten Artikel und Beiträge sowie Übersetzungen und Illustrationen, deren AutorIn er/ sie ist, im Rahmen des Persée-Programms auf nicht-exklusiver Basis online publiziert werden dürfen.

Ort

Datum

Unterschrift 